\title{
Quantitative Characterization and Dynamic Law of Interlayer Interference for Multilayer Commingled Production in Heavy Oil Reservoirs by Numerical Simulation
}

\author{
Dong Liu*, Fengyi Zhang, Qin Zhu, Xinran Wang, Jing Fan \\ Tianjin Branch of CNOOC Ltd., China National Offshore Oil Corporation, Tianjin, China \\ Email: *liudong@cnooc.com.cn
}

How to cite this paper: Liu, D., Zhang, F.Y., Zhu, Q., Wang, X.R. and Fan, J. (2019) Quantitative Characterization and Dynamic Law of Interlayer Interference for Multilayer Commingled Production in Heavy Oil Reservoirs by Numerical Simulation. World Journal of Engineering and Technology, 7, 379-395.

https://doi.org/10.4236/wjet.2019.73028

Received: June 18, 2019

Accepted: August 3, 2019

Published: August 6, 2019

Copyright $\odot 2019$ by author(s) and Scientific Research Publishing Inc. This work is licensed under the Creative Commons Attribution International License (CC BY 4.0).

http://creativecommons.org/licenses/by/4.0/

\section{cc) (i) Open Access}

\begin{abstract}
This paper moves one step forward to build a numerical model to research quantitative characterization and dynamic law for interlayer interference factor $(I I F)$ in the multilayer reservoir which was heavy oil reservoirs and produced by directional wells. There are mainly four contributions of this paper to the existing body of literature. Firstly, an equivalent simulation method of the pseudo start pressure gradient $(P S P G)$ is developed to quantitatively predict the value of IIF under different geological reservoir conditions. Secondly, the interlayer interference is extended in time, and the time period of the study extends from a water cut stage to the whole process from the oil well open to produce a high water cut. Thirdly, besides the conventional productivity interlayer interference factor $(P I I F)$, a new parameter, that is, the oil recovery interlayer interference factor $(R I I F)$ is put forward. RIIF can be used to evaluate the technical indexes of stratified development and multilayer co-production effectively. Fourthly, the effects of various geological reservoir parameters such as reservoir permeability and crude oil viscosity, etc. on the PIIF and RIIF's type curves are discussed in detail and the typical plate is plotted. The research results provide a foundation for the effective development of multilayer heavy oil reservoirs.
\end{abstract}

\section{Keywords}

Heavy Oil, Interlayer Interference, Multilayer Commingled Production, Pseudo Start Pressure Gradient, Water Flooding

\section{Introduction}

As a short-term non-renewable fossil energy, petroleum resources are very im- 
portant to today's economic and social development, affecting all aspects of people's lives. The global oil resources can be divided into several types, such as low permeability reserves, heavy oil reserves, and medium and high-permeability sandstone rare oil reserves. Low permeability and heavy oil reserves account for a large proportion. Due to low fluidity (formation permeability divided by crude viscosity), it is difficult for the reserves of low permeability and heavy oil to flow in porous media, and many scholars' studies have proved the widespread existence of pseudo start pressure gradient ( $P S P G)$ in low permeability and heavy oil [1] [2]. The so-called PSPG refers to the flow of crude oil in porous media only when the pressure gradient is exceeded. Therefore, it is an important parameter to characterize the flow threshold of oil.

In the eastern part of China, there are mainly continental sandstone reservoirs, which are characterized by multiple development strata, thin reservoir and thick oil. Its reserves and output account for about $50 \%$ of the country. A large number of geological research results show that the sandstone reservoir in China has the length of oil well section and a large number of small layers [3]. There is a large difference in permeability between multiple and interlayer. This kind of reservoir usually uses the directional well to carry out several reservoir combination development. The main advantage of this method is large well controlled reserves and high degree of reserves utilization. But at the same time, there are also obvious defects, such as serious interlayer interference, and with the production, interlayer interference is more and more serious. Therefore, the study of the subdivision sequence in the later stage of oilfield development becomes an important content of oilfield adjustment.

The heterogeneous multi-layer oilfield is composed of several or even dozens of oil layers, some of which have high permeability and low permeability. In water injection, high permeability, medium permeability and low permeability reservoirs are different in water absorption capacity, water line propulsion speed, formation pressure, oil recovery speed, water flooding and so on, so it may cause the interlayer interference [4] [5]. According to the multi wells stratified productivity test of sandstone reservoir, it is shown that the production fluid index is far less than that of the separate oil production. Interlayer interference coefficient is an important parameter to confirm the limits of layer series combination and productivity evaluation. However, interlayer interference coefficient is difficult to decide because the parameter used for calculating is hard to acquire. Then interlayer interference coefficient empirical value is usually used and some uncertainty is involved. Many scholars have studied the problem of interlayer interference. At present, the research mainly focuses on three aspects: theoretical derivation, physical experiments and numerical simulation.

$\mathrm{Wu}$ Sheng et al. [6] put forth for the first time a concept of critical permeability grade ratio for hydrocarbon injection, which based on the physical simulation experiments and the statistical analyses of practical data from oilfields. They found that when the permeability differential reaches a certain value, the fluid 
will be shielded along the high permeability layer, and the residual oil is formed, which seriously affects the efficiency of water flooding and the recovery of oil field [7] [8] [9]. Yu Huili et al. [10] qualitative analysis the main controlling factors of interlayer interference at different water cut stages, with the application of various data of dynamic production, coring inspection chamber, log interpretation data and fined reservoir research. Xian Bo et al. [11] obtained the degree of interlayer interference, technical countermeasures of eliminating the interference and corresponding technical chart for commingled production in thin reservoirs by using dual model without interlayer channeling, numerical simulation and analysis of single and orthogonal factors. However, the effect of different pressure coefficient and formation permeability is only considered. Wang Shibo et al. [12] through the numerical simulation test, the influence degree of various factors on recovery can be obtained, and the oil recovery of various factors can be obtained by regression. When there is no interlayer interference well testing, Liu Hongjie [13] proposed using reservoir engineering method to calculate interlayer interference coefficient with DST test data, dynamic performance data, pressure buildup test interpretation results, PVT and core analysis results, and so on. In view of the present few theoretical researches on the quantitative characterization of interlayer interference in multi-layer commingled sandstone reservoirs, Su Yanchun et al. [14] proposed a new concept of interlayer dynamic interference, and established a mathematical model for the quantitative characterization of the dynamic interference coefficient between layers. The quantitative relationship between the dynamic interference coefficient of the multi-layer combined production sandstone reservoir and the water content of the longitudinal layers, the permeability and the pressure difference of the combined production pressure is deduced by the seepage theory. However, the research only analyzed the influence of formation permeability and formation crude viscosity on production capacity interference factor $(P I I F)$, the oil recovery interference factor $(R I I F)$ is not analyzed.

At present, the main research method of interlayer interference is the stratified productivity test of oil well. The advantage of this method is that it can get first-hand information of interlayer interference, and its disadvantage is high cost. Therefore, usually the test data are few, and from the test itself, we cannot understand the interference factors and their change rules. In addition, in addition to the difference in physical property, the difference between the pressure and water content of the longitudinal layers is becoming more and more, and the interference is further aggravated. Huang Shijun et al. [15] quantitatively characterized the interlayer interference in multilayer commingled production of ordinary offshore heavy oil reservoirs, and established an appropriate productivity prediction method of directional wells for multilayer commingled production of ordinary heavy oil reservoirs based on the physical experiment of visible multi-tube water flooding. They get an interesting conclusion that interlayer interference is mainly controlled by vertical reservoir permeability difference, and 
proposed that it can be comprehensively characterized by reservoir reference permeability, permeability contrast and permeability deviation.

At the same time, the reservoirs with multilayer water injection have the problems of injection water quick braking through and low oil recovery in water-free oil production period, and the middle and high water cut period become the main oil producing period [16]. Therefore, it is very important to determine the influence of interlayer interference on oil well productivity at different water cut stages, especially in middle and high water cut period. Considering the characteristics of short production years and high development cost of offshore oil fields [17], it is of great significance to accurately evaluate the productivity of oil wells, to reasonably divide the development layer, and to take the corresponding technical countermeasures to eliminate or reduce the impact of interlayer interference on the efficient development of offshore oil fields.

All of these previous works laid a solid foundation for later research. However, these works were not focused on pseudo start pressure gradient (PSPG). These previous models are no longer applicable for heavier oil with $P S P G$. In recent years, pioneer works were conducted on the flow behaviors of heavy oil with $P S P G$. Wang Shoulei et al. [18] proposed a new method to determine interlayer interference coefficient by considering $P S P G$ in reservoir simulation. Based on the consideration of periodicity and dynamic characteristics, Xu Jiafeng et al. [19] established the dynamic interference mathematic model of multilayer commingle producing for water flooding sand stone heavy oil. And the effects of such main factors as permeability, viscosity and threshold pressure gradient on interlayer interference are revealed.

At present, there are many studies on interlayer interference, but most of the conclusions are only suitable for single phase flow or only for a certain water cut stage [20] [21] [22], or describing qualitatively the interference phenomena at various stages based on a rough division of the production stage according to the field situation [8] [10] [13]. This has little guiding significance for actual production. However, the dynamic law and recovery interference factor in multilayer co-production are still not clear.

This paper moves one step forward to build numerical model to research quantitative characterization and dynamic law for IIF when multilayer commingled production by directional wells in heavy oil reservoirs. There are mainly four contributions of this paper to the existing body of literature. Firstly, an equivalent simulation method of the $P S P G$ is developed to quantitatively predict the value of IIF under different geological reservoir conditions. Secondly, the interlayer interference is extended in time, and the time period of the study extends from a water cut stage to the whole process from the oil well open to produce to high water cut. Thirdly, besides the conventional PIIF, a new parameter, that is, the RIIF is put forward. RIIF can be used to evaluate the technical indexes of stratified development and multilayer co-production effectively. Fourthly, effect of various geological reservoir parameters such as reservoir permeability and 
crude oil viscosity, etc. on the PIIF and RIIF's type curves are discussed in detail and the typical plate are plotted. The research results provide a foundation for the effective development of multilayer heavy oil reservoirs.

\section{Methods and Models}

\subsection{Definition of Interference Coefficients}

To better characterize the interference, three interference coefficients can be defined as follows:

$$
\begin{aligned}
P I I F_{l} & =\frac{\sum_{i=1}^{n} S P I_{s l i}-\sum_{i=1}^{n} S P I_{m l i}}{\sum_{i=1}^{n} S P I_{s l i}} \\
P I I F_{o} & =\frac{\sum_{i=1}^{n} S P I_{s o i}-\sum_{i=1}^{n} S P I_{m o i}}{\sum_{i=1}^{n} S P I_{s o i}} \\
R I I F & =\frac{\sum_{i=1}^{n} R F_{s o i}-\sum_{i=1}^{n} R F_{m o i}}{\sum_{i=1}^{n} R F_{s o i}}
\end{aligned}
$$

The physical significance of the interference coefficient is the degree to which the overall fluid productivity and oil production capacity of the multi-layer well are reduced by interlayer interference under the same water-cut condition when mingled injection and production.

\subsection{Establishment of Numerical Model Considering Pseudo-Start-Up Pressure Gradient}

The numerical model is available by the ECLIPSE reservoir simulator, which is shown in Figure 1. In addition, the grid system is $31 \times 31 \times 12$ and the corresponding block dimensions in $I, J$ and $K$ directions are $5.0 \mathrm{~m}, 5.0 \mathrm{~m}$ and $4.0 \mathrm{~m}$, respectively. And the border is a closed border. The reservoir has two oil layers, the upper layer and lower layer has the same thickness of $20 \mathrm{~m}$. The $1-5^{\text {th }}$ layer is the upper layer, the $6^{\text {th }}$ layer is the mudstone interlayer, the $7-11^{\text {th }}$ layer is the lower layer, and the $12^{\text {th }}$ layer is the mudstone interlayer. In the model, the water is injected by directional well I1 located in the center of left, and the production well P2 located in the center of right, which can be seen as a quarter of the reverse five point pattern.

The $P S P G$ of heavy oil can be simulated by the following method. If the threshold pressure between the two equilibrium partitions is set up as the pseudo start pressure (the product of the $P S P G$ and the mesh size), the equivalent simulation of the $P S P G$ can be achieved [20]. The equivalent simulation of the PSPG using the THPRES keyword is divided into two steps. First, the balance partition of the grid is set up, and second the threshold pressure between the different 


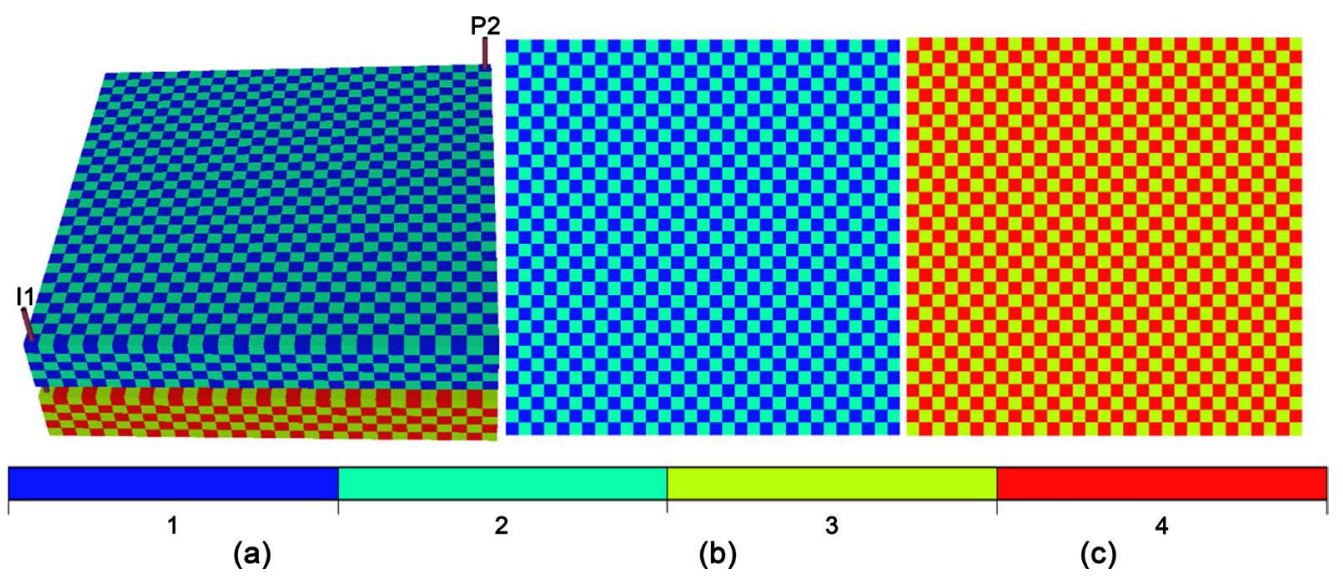

Figure 1. Equilibrium zones schematic diagram of numerical simulation model for (a) three dimensional grid, (b) the upper layer, (c) the lower layer.

partitions is set. The setting of balanced partition takes the following methods: the first grid in line 1 is set as balanced partition 1, and the second grid is set as balanced partition 2, which is repeated until the end of the line. The first grid in line 2 is set as balanced partition 2, and the second grid is set as balanced partition 1. Repeat until the end of the row. The other rows will be repeated in line 1 and line 2 Settings. As shown in Figure 1(a) and Figure 1(b), for any grid, its balanced partition is different from that of the four adjacent grids, and the threshold pressure of two balanced partitions must be overcome for fluid flow from the grid to any grid.

Luo Xiaobo et al. [21] used sand filling pipes for physical simulation experiments in 3 heavy oil fields in Bohai sea area (crude oil viscosity 49.2 - 135.0 $\mathrm{mPa} \cdot \mathrm{s}$ ) and the main oil sands (permeability $632-3265 \mathrm{mD}$ ). According to the reference [21], the relationship between $P S P G$ and fluidity obtained through regression was as follows:

$$
P S P G=0.1231 \times\left(\frac{K}{\mu_{o}}\right)^{-0.8688}
$$

Taking the first layer as an example, the permeability of this layer is 10,000 $\mathrm{mD}$, and the viscosity of crude oil is $300 \mathrm{mPa} \cdot \mathrm{s}$. The calculation results by formula (4) show that the $P S P G$ is $0.00585 \mathrm{MPa} / \mathrm{m}$. Due to the grid size is $5 \mathrm{~m}$, so the threshold pressure between adjacent zones is $0.029 \mathrm{MPa}$.

\subsection{Validation of Model Prediction Results}

Based on the geological reservoir parameters of the $S$ heavy oil reservoir in Bohai oilfield, a homogeneous geological model is established, and the comparison between the interlayer interference coefficient of the 5 wells in the $S$ reservoir and the field test results is calculated [15], as shown in Table 1. It can be seen from Table 1 that the inter-layer interference coefficient obtained by considering the PSPG is consistent with the field test results as shown in Figure 2, which verifies the correctness of the model and the adopted method in this paper. 
Table 1. The interference coefficient comparison between reported in the literature and calculated by above numerical model based on the S heavy oil field.

\begin{tabular}{ccc}
\hline Well Name & Value for Field Test Result & Value for above Numerical Model \\
\hline A04 & 0.57 & $/$ \\
A11 & 0.46 & $/$ \\
A25 & 0.54 & $/$ \\
A14 & 0.35 & $/$ \\
B6 & 0.53 & 0.457 \\
Average Value & 0.49 &
\end{tabular}

Annotation: Value for above Numerical Model is the average value for the first produce month.

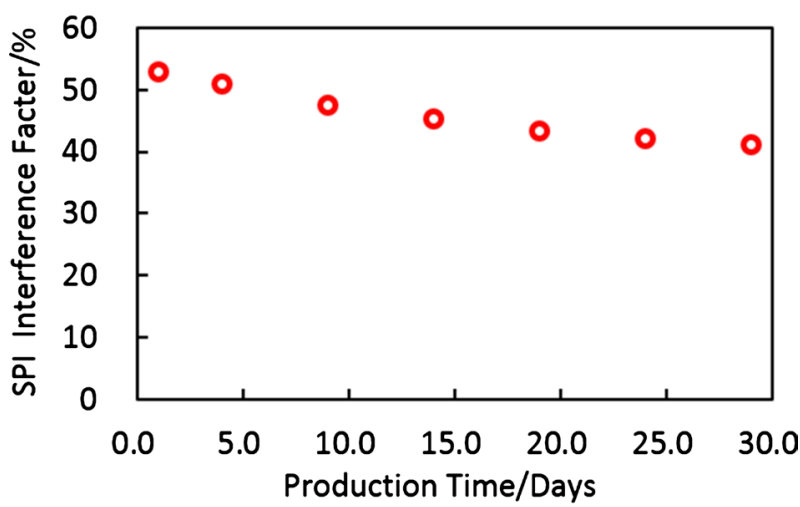

Figure 2. The oil production index interference coefficient calculated by the above model changes with time.

\section{Program Design and Research Results}

In this paper, the effects of formation permeability and oil viscosity on interlayer interference are considered.

For the study of formation permeability, the viscosity of formation oil is constant at $300 \mathrm{mPa} \cdot \mathrm{s}$, and the permeability of upper reservoir is constant at $10 \mu \mathrm{m}^{2}$, and the permeability of lower reservoir is different under different schemes (15 range Max/Min values are studied) to obtain 15 geological reservoir models. Each model studies the three development scheme: only produce the upper oil layer, only produce the lower oil layer and mingled produce the two-layers respectively.

For the study of oil viscosity, the permeability of formation is constant at 2.5 $\mu \mathrm{m}^{2}$, and the oil viscosity of upper reservoir is constant at $300 \mathrm{mPa} \cdot \mathrm{s}$, and the lower reservoir is different under different schemes (15 range Max/Min values are studied) to obtain 15 geological reservoir models. The $P S P G$ of different combination schemes is calculated according to formula 4 . The parameters and calculation results of the model design are shown in Table 2.

\section{Discussion}

\subsection{Formation Oil Viscosity}

For the oilfield in initial production period, the production capacity is mainly 
Table 2. The parameters and values in the scheme design and the results.

\begin{tabular}{|c|c|c|c|c|c|c|c|c|}
\hline \multirow[b]{2}{*}{$\mathrm{Max} / \mathrm{mix}$} & \multicolumn{4}{|c|}{ Formation Permeability } & \multicolumn{4}{|c|}{ Oil Viscosity } \\
\hline & $\begin{array}{l}\text { Upper } \\
\text { Layer } \\
\left(\mu \mathrm{m}^{2}\right)\end{array}$ & $\begin{array}{l}\text { Lower } \\
\text { Layer } \\
\left(\mu \mathrm{m}^{2}\right)\end{array}$ & $\begin{array}{c}\text { Recovery } \\
\text { Single } \\
(\%)\end{array}$ & $\begin{array}{c}\text { Recovery } \\
\text { Mingled } \\
(\%)\end{array}$ & $\begin{array}{l}\text { Upper } \\
\text { Layer } \\
(\mathrm{mPa} \cdot \mathrm{s})\end{array}$ & $\begin{array}{l}\text { Lower } \\
\text { Layer } \\
(\mathrm{mPa} \cdot \mathrm{s})\end{array}$ & $\begin{array}{c}\text { Recovery } \\
\text { Single } \\
(\%)\end{array}$ & $\begin{array}{c}\text { Recovery } \\
\text { Mingled } \\
(\%)\end{array}$ \\
\hline 1 & 10 & 10.00 & 30.1 & 31.1 & 300 & 300.0 & 28.7 & 28.8 \\
\hline 2 & 10 & 5.00 & 29.5 & 26.9 & 300 & 150.0 & 30.9 & 28.4 \\
\hline 3 & 10 & 3.33 & 29.4 & 22.6 & 300 & 100.0 & 32.3 & 27.9 \\
\hline 4 & 10 & 2.50 & 29.4 & 19.7 & 300 & 75.0 & 33.4 & 27.6 \\
\hline 5 & 10 & 2.00 & 29.1 & 18.2 & 300 & 60.0 & 34.2 & 27.6 \\
\hline 6 & 10 & 1.67 & 26.7 & 17.1 & 300 & 50.0 & 35.0 & 27.1 \\
\hline 7 & 10 & 1.43 & 24.8 & 16.5 & 300 & 42.9 & 35.7 & 26.7 \\
\hline 8 & 10 & 1.25 & 22.9 & 16.1 & 300 & 37.5 & 36.2 & 26.8 \\
\hline 9 & 10 & 1.11 & 21.3 & 15.9 & 300 & 33.3 & 36.7 & 26.7 \\
\hline 10 & 10 & 1.00 & 19.6 & 15.8 & 300 & 30.0 & 37.1 & 26.8 \\
\hline 11 & 10 & 0.91 & 18.1 & 15.7 & 300 & 27.3 & 37.5 & 26.9 \\
\hline 12 & 10 & 0.83 & 16.9 & 15.6 & 300 & 25.0 & 37.9 & 27.0 \\
\hline 13 & 10 & 0.77 & 16.0 & 15.5 & 300 & 23.1 & 38.1 & 27.1 \\
\hline 14 & 10 & 0.71 & 15.5 & 15.5 & 300 & 21.4 & 38.4 & 27.2 \\
\hline 15 & 10 & 0.67 & 15.4 & 15.4 & 300 & 20.0 & 38.6 & 27.4 \\
\hline
\end{tabular}

affected by the static parameters of the geological reservoir. Therefore, this paper focuses on the influence of the formation permeability and the oil viscosity under formation conditions on the interlayer interference.

\subsubsection{Specific Productivity Index}

Specific productivity index $(S P I)$ is an important indicator to measure the daily oil production capacity of the reservoir. The physical significance of this index is the daily oil production capacity per unit reservoir thickness per unit pressure difference. The larger the value, the stronger the oil production capacity of the oilfield. In case of Max/Min $=5$, the variation law of the $S P I$ with production time is shown in Figure 3.

It can be seen from Figure 3(a) that the change of SPI can be divided into three stages when producing the lower oil layer (with formation oil viscosity 60 $\mathrm{mPa} \cdot \mathrm{s})$ separately. The first stage, the stable production stage at the initial stage of production, and the $S P I$ is constant. In the second stage, rapid decline stage, after two months of production, the $S P I$ decreased from 4.9 to 2.2, with a decline amplitude of $55 \%$. The third stage, slow decline stage, slow decline of SPI. When producing the upper oil layer (with formation oil viscosity $300 \mathrm{mPa} \cdot \mathrm{s}$ ) separately, the $S P I$ is nearly constant. So, when the two layers are produced combined, SPI presents the same periodic characteristics as that of producing lower reservoir separately. For water production, it can be seen from Figure 3(b) that the water 
production capacity of reservoirs with relatively thin viscosity is increasing at the later stage, while the fluid production capacity of reservoirs with high crude oil viscosity is basically unchanged.

\subsubsection{Specific Productivity Index Interference Factor}

Figure 4 is a comparison diagram of the PIIF between the upper reservoir and the lower reservoir under different Max/Min values. As shown in the above figure, the greater the difference of formation crude oil viscosity, the earlier the water injection breakthrough time. Correspondingly, the earlier the water breakthrough in the upper reservoir, the earlier the inflection point of PIIF appears. In this mod$\mathrm{el}$, for the case of $\mathrm{max} / \mathrm{min}=5$, the maximum $P I I F$ is $55.6 \%$ after producing 74 days, and for the case of $\mathrm{max} / \mathrm{min}=10$, the maximum PIIF is $56.2 \%$ after producing 52 days.

Figure 5 is the isogram of oil saturation at different production times under the condition of formation crude oil viscosity at $\mathrm{Max} / \mathrm{Min}=10$. It can be seen from Figure 5 that the periodic change rule of the interference coefficient of the specific oil recovery index corresponds to the periodic change of oil saturation field. Specifically, the rule of interlayer interference is summarized as follows: at the initial stage of production, because the crude oil in the lower reservoir is low and the seepage resistance is relatively small, the injected water first enters the production well along the lower reservoir, showing that the lower reservoir has a

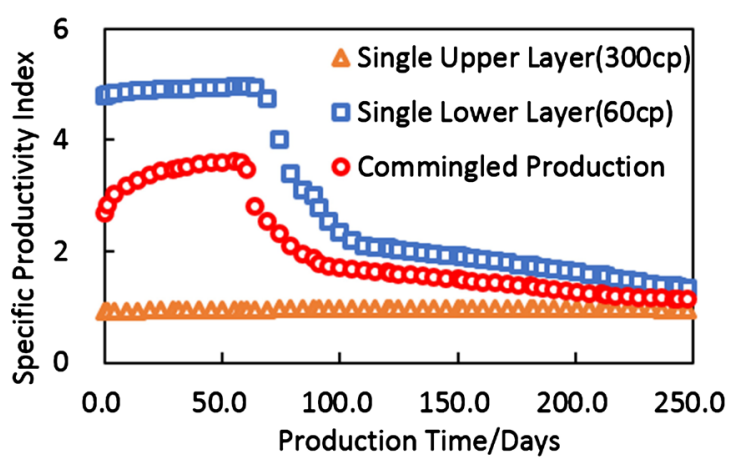

(a)

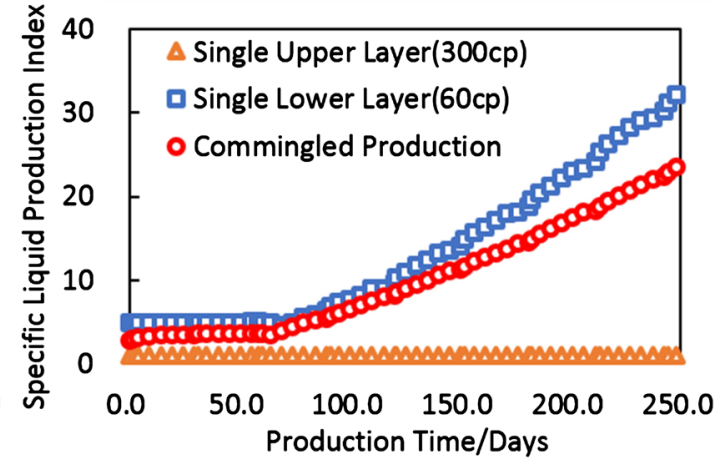

(b)

Figure 3. SPI figure of formation oil viscosity $\max / \min =5$ for (a) oil, (b) oil add water.

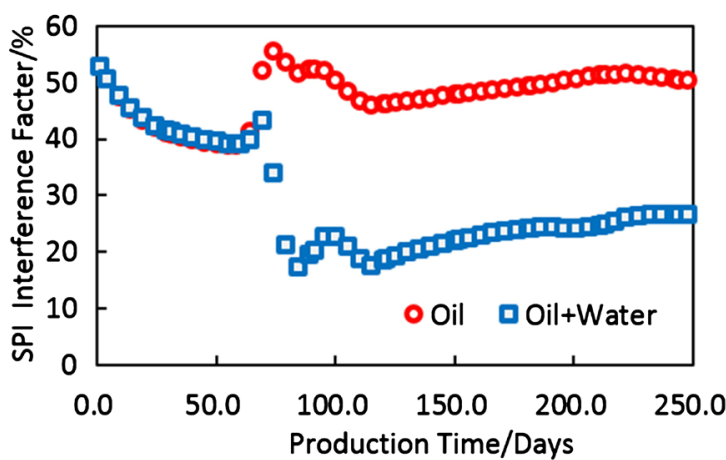

(a)

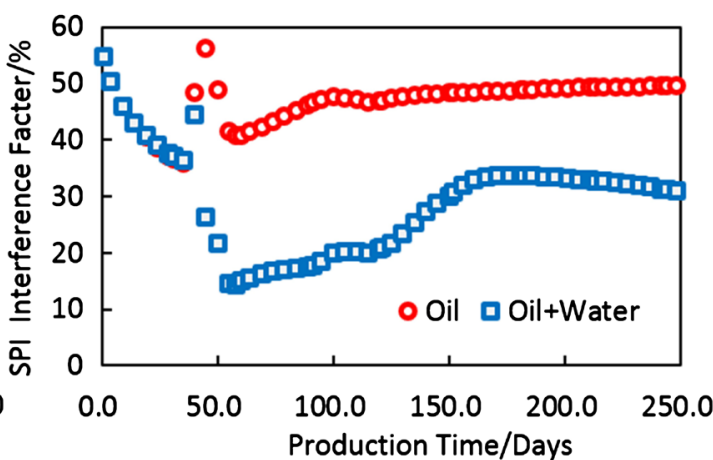

(b)

Figure 4. PIIF contrast figure of formation oil viscosity for (a) $\max / \min =5$, (b) $\max / \min =10$. 


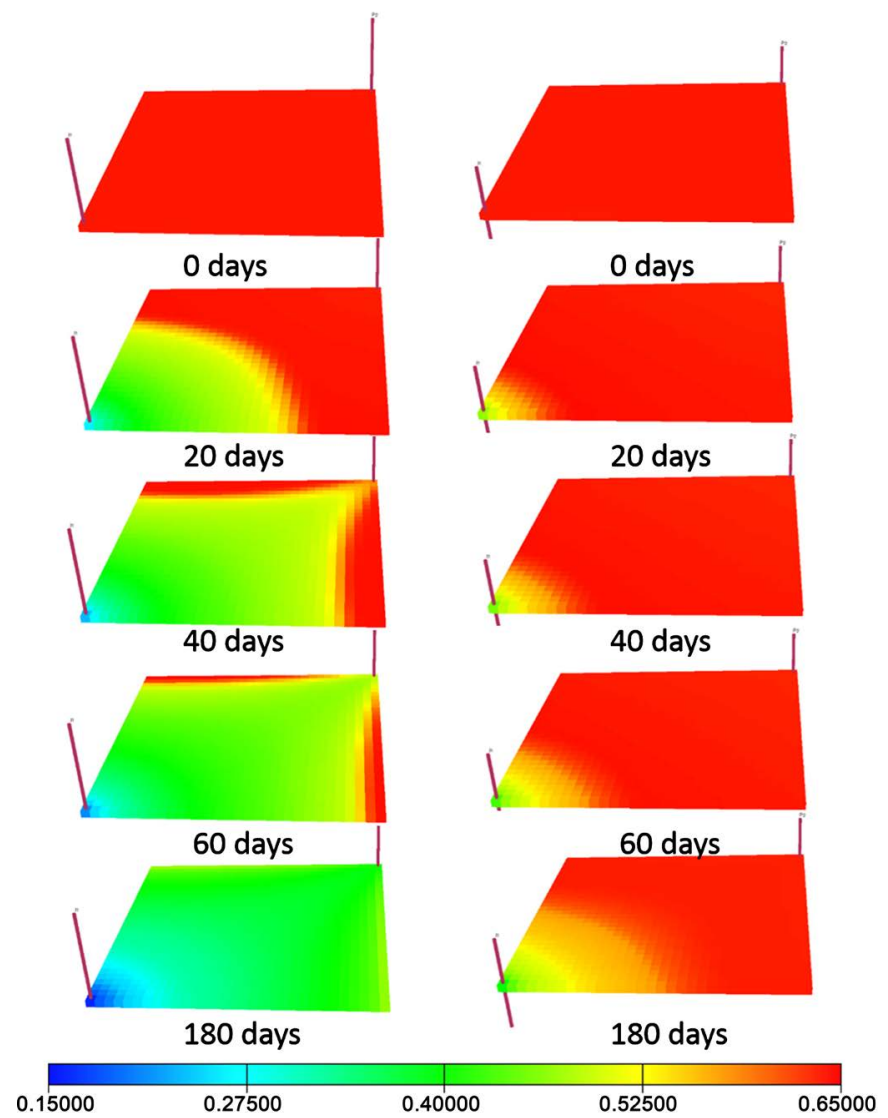

Figure 5. Oil saturation field varied with production time of the case formation oil viscosity $\mathrm{max} / \mathrm{min}=10$ (the left is the lower layer with $30 \mathrm{mPa} \cdot \mathrm{s}$, and the right is the upper layer with $300 \mathrm{mPa} \cdot \mathrm{s})$.

higher SPI, while the upper reservoir has a lower SPI. With the development of production, the PIIF decreases gradually. When the injected water breaks through to the production well along the main line of the lower reservoir, the $S P I$ of the lower reservoir begins to reduce greatly. As the breakthrough became more and more serious, the $S P I$ in the lower oil layer began to decline slowly. Therefore, the curve of PIIF shows two distinct stages. In the first stage, before the injected water breaks through the production well, the PIIF drops slowly. In the second stage, after the injected water broke through the production well, the disturbance coefficient was basically stable around a certain value.

\subsubsection{Oil Recovery Degree Interference Factor}

The PIIF is mainly used for the judgment of a certain stage, while for the evaluation of the entire development stage, another parameter, RIIF is more effective. Figure 6 is the figure of oil recovery degree varied with $\mathrm{max} / \mathrm{min}$ formation oil viscosity of commingled production.

It can be seen from Figure 6(a) that for the oil reservoirs with different crude viscosity in the upper and lower reservoirs, the recovery degree of the upper and lower reservoirs varies with the increment of the viscosity difference. As the viscosity of the upper reservoir keeps constant at $300 \mathrm{mPa} \cdot \mathrm{s}$, its recovery degree decreases 


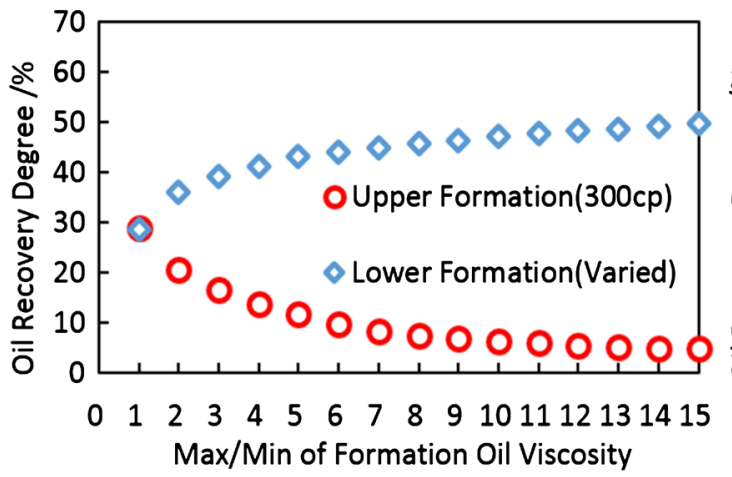

(a)

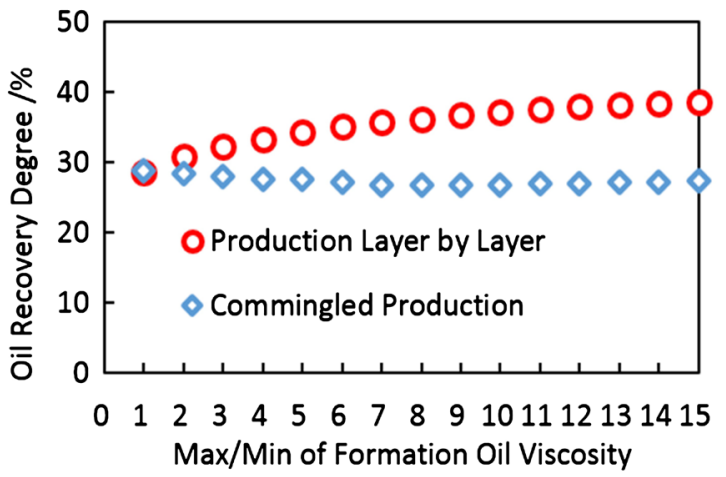

(b)

Figure 6. Oil recovery degree varied with $\mathrm{max} / \mathrm{min}$ formation oil viscosity of commingled production. (a) Upper and lower layer comparison; (b) Different production ways comparison.

greatly with the decrease of the lower layer viscosity difference. When the viscosity difference ( $\mathrm{max} / \mathrm{min}$ value) increased from 1 to 15 , the recovery degree of the upper reservoir decreased from $29.0 \%$ to $4.8 \%$. And with the increase of the viscosity difference, the recovery degree of the upper reservoir showed a law of logarithmic decline. As the viscosity of the lower reservoir gradually decreased from $300 \mathrm{mPa} \cdot \mathrm{s}$ to $20 \mathrm{mPa} \cdot \mathrm{s}$, the recovery degree of the lower reservoir increased from $28.6 \%$ to $49.8 \%$. And the recovery degree of the lower reservoir presented a law of logarithmic function.

$$
\begin{aligned}
& R F_{\text {Upper }}=-8.759 \ln \left(\operatorname{Max}_{\text {viso }} / \operatorname{Min}_{\text {viso }}\right)+26.774\left(R^{2}=0.9743\right) \\
& R F_{\text {Lower }}=7.3435 \ln \left(\text { Max }_{\text {viso }} / \text { Min }_{\text {viso }}\right)+30.368\left(R^{2}=0.9849\right)
\end{aligned}
$$

For different development methods (commingled production and separated production), the ultimate recovery degree of the whole reservoir is different. It can be clearly seen from Figure 6(b) that, with the increase of crude oil viscosity extreme difference, the oil recovery of commingled production changes slightly, while that of produce layer by layer significantly increases.

$$
R I F_{\text {viso }}=11.195 \ln \left(\text { Max }_{\text {viso }} / \operatorname{Min}_{\text {viso }}\right)+1.2382\left(R^{2}=0.9783\right)
$$

Figure 7 shows the relationship between the RIIF and the Max/Min oil viscosity. As the Max/Min viscosity increases, the RIIF increases in logarithmic form. When the Max/Min is less than 5, the increase speed is faster. When the Max/Min is between 5 and 10, the increase rate becomes slow. When the Max/Min is greater than 10 , the RIIF is stable at about $30 \%$. Therefore, in order to obtain a better development effect, it is recommended to conduct stratified mining when the Max/Min viscosity is greater than 5 .

\subsection{Formation Permeability}

\subsubsection{Specific Productivity Index}

It can be seen from Figure 8(a) that the change of $S P I$ can be divided into three stages when producing the upper oil layer (with formation permeability 10,000 $\mathrm{mD}$ ) separately. The first stage, the stable production stage at the initial stage of 


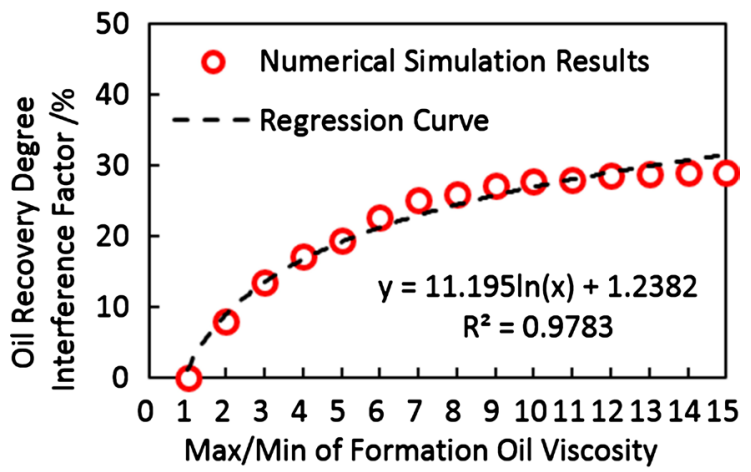

Figure 7. Oil recovery degree interference factor (RIIF) varied with $\max / \mathrm{min}$ formation oil viscosity.

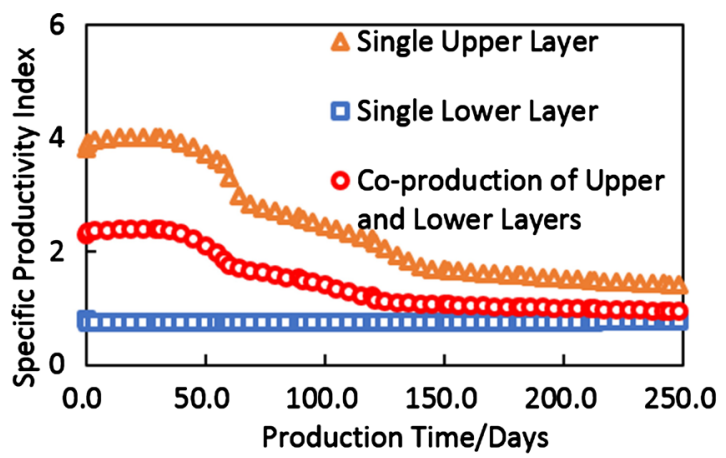

(a)

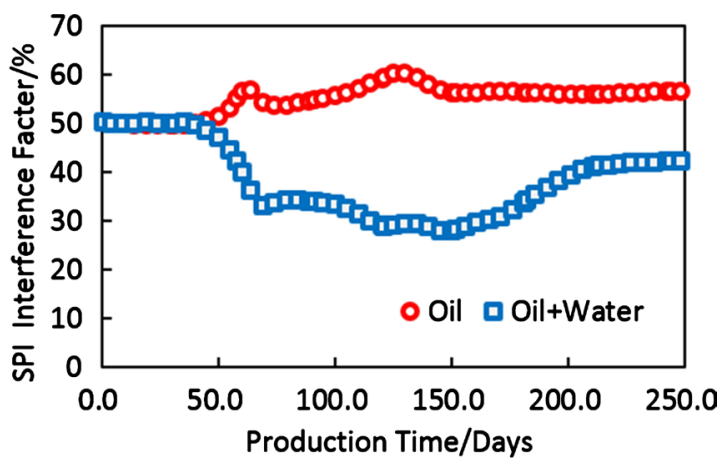

(b)

Figure 8. SPI and PIIF of formation permeability $\max / \mathrm{min}=5$ for (a) $S P I$, (b) PIIF.

production, and the $S P I$ is constant. In the second stage, rapid decline stage, after two months of production, the $S P I$ decreased from 4.0 to 2.8 , with a decline amplitude of $30 \%$. The third stage, SPI declines slowly. When producing the lower permeability oil layer separately, the $S P I$ is nearly constant. So, when the two layers are produced combined, $S P I$ presents the same periodic characteristics as that of producing upper reservoir separately.

As shown in Figure 8(b), the greater the difference of formation permeability, the earlier the water injection breakthrough time. Correspondingly, the earlier the water breakthrough in the upper reservoir, the earlier the inflection point appears in the PIIF. In this model, for the case of $\max / \min =5$, there are two peak points, one occurs after produce 50 days, with the PIIF of $56.7 \%$, and the other occurs after produce 150 days, with the PIIF of $60.2 \%$. This characteristic is corresponds to the periodic change of oil saturation field, which has been showed in Figure 9.

\subsubsection{Oil Recovery Degree Interference Factor}

Figure 10 is the figure of oil recovery degree varied with $\mathrm{max} / \mathrm{min}$ formation permeability of commingled production. It can be seen from Figure 10(a) that for the oil reservoirs with different permeability in the upper and lower reservoirs, the recovery degree of the upper and lower reservoirs varies with $\mathrm{max} / \mathrm{min}$ formation permeability. As the permeability of the upper reservoir keeps constant at $10,000 \mathrm{mD}$, its recovery degree increases slightly with the increase of the 


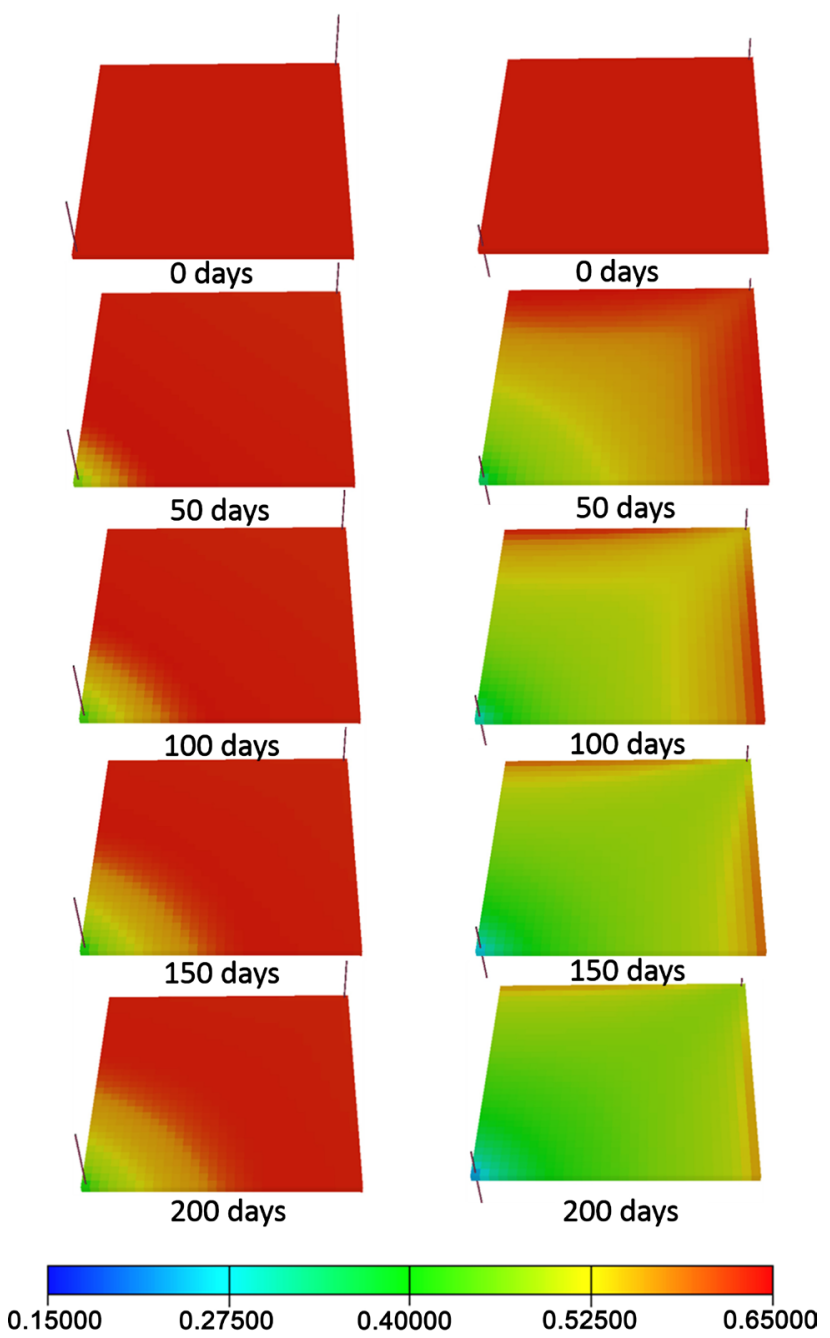

Figure 9. Oil saturation field varied with production time of the case formation permeability $\max / \mathrm{min}=5$ (the left is the lower layer with $2000 \mathrm{mD}$, and the right is the upper layer with $10,000 \mathrm{mD}$ ).

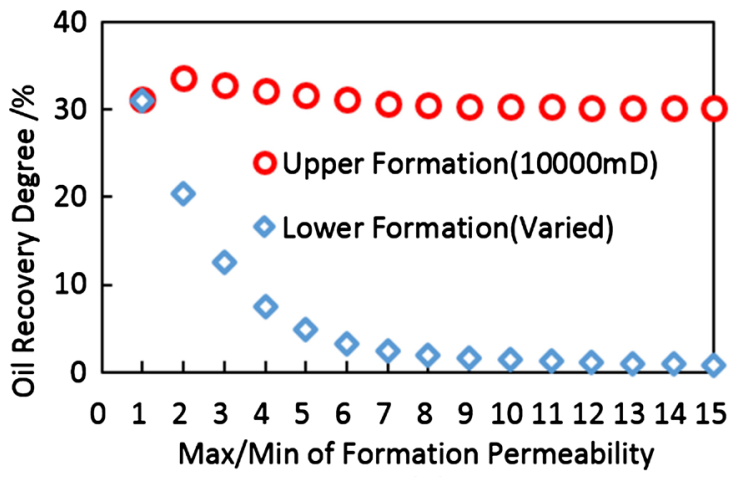

(a)

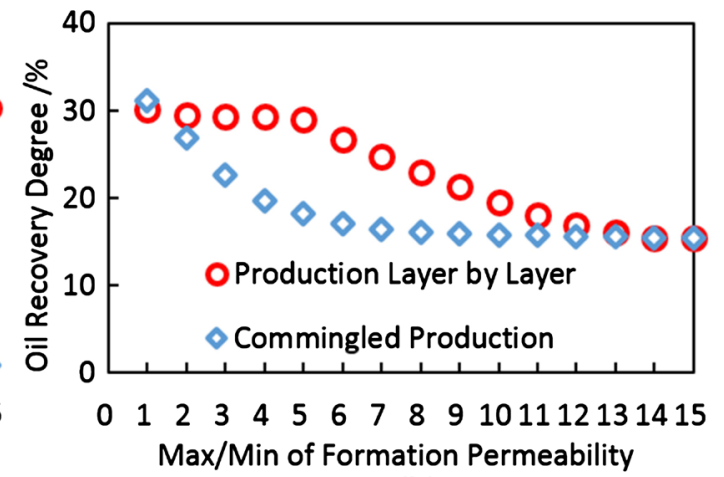

(b)

Figure 10. Oil recovery degree varied with $\mathrm{max} / \mathrm{min}$ formation permeability of commingled production. (a) Upper and lower layer comparison; (b) Different production ways comparison.

permeability difference, and keep at about $30 \%$. But the lower formation, its recovery degree decrease greatly with the increase of the permeability difference. When the permeability difference ( $\max / m i n$ value) increased from 1 to 15 , the 
recovery degree of the lower reservoir decreased from $31.0 \%$ to $0.8 \%$. And with the increase of the $\mathrm{max} / \mathrm{min}$ value, the recovery degree of the lower reservoir showed a law of power function decline.

$$
R F_{\text {Lower }}=47.104\left(\operatorname{Max}_{\text {perm }} / \operatorname{Min}_{\text {perm }}\right)^{-1.495}\left(R^{2}=0.9788\right)
$$

It can be clearly seen from Figure 10(b) that, with the increase of formation permeability extreme difference, the oil recovery of combined mining changes from $30.0 \%$ to $15.4 \%$, while that of single mining significantly increases at first, and decreased to the same value after $\mathrm{max} / \mathrm{min}$ formation permeability larger than 12 .

Figure 11 shows the relationship between the RIIF and the Max/Min permeability, and can be regressed as:

$$
\begin{aligned}
R_{\text {Perm }}= & 0.0957\left(\operatorname{Max}_{\text {perm }} / \operatorname{Min}_{\text {perm }}\right)^{3}-2.9485\left(\operatorname{Max}_{\text {perm }} / \operatorname{Min}_{\text {perm }}\right)^{2} \\
& -24.531\left(R^{2}=0.9863\right)
\end{aligned}
$$

As the Max/Min permeability increases, the RIIF presents the characteristics of two stages. When the Max/Min is less than 5, the increase speed is faster. When the Max/Min is higher than 5, the RIF begins to decrease. The main reason is that with the decrease of formation permeability, the starting pressure gradient of low permeability layer increases continuously and the seepage resistance increases, leading to the injection water breakthrough along the high permeability layer with relatively small seepage resistance, resulting in low water flooding sweep coefficient of low permeability layer. When the $\max / \mathrm{min}$ formation permeability is greater than 5 , the recovery degree of low permeability layer is only $4.8 \%$. When the $\mathrm{max} / \mathrm{min}$ formation permeability is greater than 10 , the recovery degree of low permeability layer is only $1.4 \%$. Therefore, in order to obtain a better produce effect, it is recommended to conduct stratified mining when the Max/Min viscosity is greater than 5 .

\subsection{Strengths and Limitations}

The innovation of this paper is that by establishing the numerical simulation

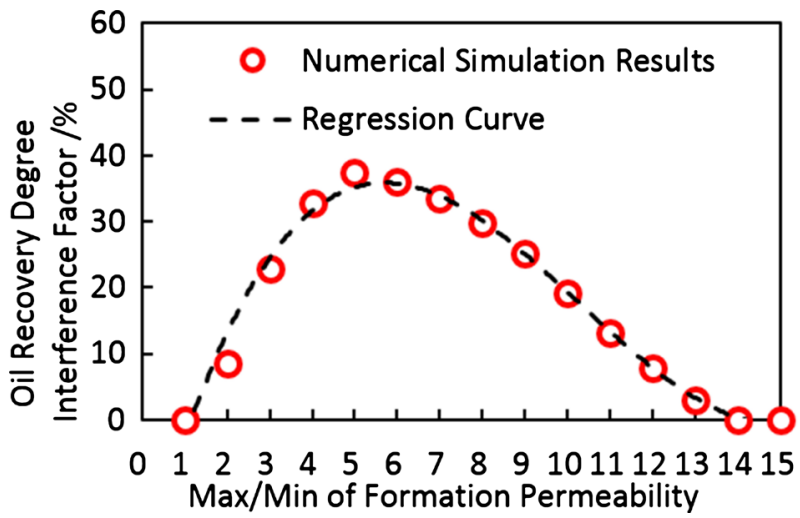

Figure 11. Oil recovery degree interference factor (RIIF) varied with $\mathrm{max} / \mathrm{min}$ formation permeability. 
model considering the PSPG of heavy oil, the variation law of the interference coefficient between the two reservoirs with different crude oil viscosity and different permeability differences is successfully simulated. At the same time, in order to more accurately judge the influence of combined mining and separate mining on the oilfield development effect, the concept of RIIF is defined, which makes up for the insufficiency of the PIIF which only represents the value of a certain stage, and represents a final effect. Through the study, we get the limit of using the reservoir with high seepage resistance under different conditions. The results of the study provide a selection condition for the selection of multi-layer sandstone reservoir for the development of stratified system, especially for the design of oilfield development scheme.

Although some achievements have been made in this paper, there are still some areas for further study. For example, the study in this paper is based on the homogeneous model without considering the effect of in-layer plane heterogeneity. It can be speculated that, for planar heterogeneous reservoirs, the law of water injection breakthrough is different from that of homogeneous reservoirs, which may lead to the difference of interlayer interference coefficient. However, this does not affect the general understanding of the interference coefficient and interference law of two-layer heavy oil reservoirs.

\section{Conclusions}

Through efforts, this paper aims at the problem of dynamic rule and quantitative description of interlayer interference in the co-production of heavy oil reservoirs, and obtains several important understandings, which are as follows:

1) A novel equivalent simulation method of the pseudo start pressure gradient $(P S P G)$ is developed to quantitatively predict the value of PIIF. The interlayer interference is extended in time, and the time period of the study extends from a water cut stage to the whole process from the oil well open to produce a high water cut.

2) Based on the conventional production capacity interference factor (PIIF), a new parameter, that is, the oil recovery interference factor $(R I I F)$ is put forward. $R I I F$ can be used to evaluate the technical indexes of stratified development and multilayer co-production.

3) The effects of various geological reservoir parameters such as permeability, crude oil viscosity, etc. on the PIIF and RIIFs type curves are discussed in detail. The PIIF and RIIF under different range conditions are plotted. In order to obtain a better development effect, it is recommended to conduct stratified mining when the Max/Min viscosity is greater than 5 or the Max/Min permeability is greater than 5 .

\section{Acknowledgements}

This work was supported by the National Science and Technology Major of China (2016ZX05058-001-008), which was named optimization and application 
of thermal recovery in offshore heavy oil fields.

\section{Conflicts of Interest}

The authors declare no conflicts of interest regarding the publication of this paper.

\section{References}

[1] Dou, H., Ma, S., Zou, C., et al. (2014) Threshold Pressure Gradient of Fluid Flow through Multi-Porous Media in Low and Extra-Low Permeability Reservoirs. Science China (Earth Sciences), 57, 2808-2818. https://doi.org/10.1007/s11430-014-4933-1

[2] Liu, D., Li, X., Liu, J., et al. (2017) Mesoscopic Mechanism of Threshold Pressure Gradient in Low Permeability Porous Media. Journal of Engineering Thermophysics, 38, 787-791.

[3] Han, D. and Wan, R. (1999) The Development Models of Multizone Sandstone Reservoirs. Petroleum Industry Press, Beijing, 132-145.

[4] Wang, Z. and Shi, Z. (1999) Advanced Reservoir Characterization Technology. Petroleum Industry Press, Beijing, 251-258.

[5] Xiong, Q., Wang, Z. and Ji, F. (1994) The Modern Reservoir Description Technique and Its Application in China. Acta Petrolei Sinica, 15, 1-9.

[6] Wu, S., Zeng, J., Lin, S., et al. (2003) Interlayer Interference and Differential Injection of Hydrocarbon into a Trap. Petroleum Geology \& Experiment, 25, 285-288.

[7] Weber, K.J. (1986) How Heterogeneity Affects Oil Recovery. In: Lake, L.W. and Carroll, H.B., Eds., Reservoir Characterization, Academic Press, Orlando, 487-544. https://doi.org/10.1016/B978-0-12-434065-7.50021-6

[8] Chen, Y. (1993) Countermeasures for Heterogeneity of Continental. Petroleum Industry Press, Beijing.

[9] Wu, S. and Xiong, Q. (1998) Oil and Gas Reservoir Geology. Petroleum Industry Press, Beijing.

[10] Yu, H., Wang, W., Rong, N., et al. (2006) Rule of Interlayer Interference in Various Water Cut Periods of Shengtuo Oilfield. Petroleum Geology and Recovery Efficiency, 13, 71-73.

[11] Xian, B., Xiong, Y., Shi, G., et al. (2007) Interlayer Interference Analysis of Commingled Production in Thin Reservoirs and Its Technical Countermeasures. Special Oil \& Gas Reservoirs, 14, 51-54.

[12] Wang, S., Huang, A. and Wei, J. (2012) Numerical Simulation on Interlayer Interference of Thin and Interbed Reservoirs. Journal of Oil and Gas Technology, 34, 247-250.

[13] Liu, H. (2013) New Determination Method of Interlayer Interference Coefficient among Commingling Production Layers in Conventional Reservoirs. Petroleum Geology and Engineering, 27, 50-82.

[14] Su, Y., Jia, X., Li, Y., et al. (2015) New Technology for Quantitative Characterization of Interlayer Dynamic Interference in Multi-Layer Commingled Production Reservoirs. Special Oil \& Gas Reservoirs, 22, 101-103.

[15] Huang, S., Kang, B., Cheng, L., et al. (2015) Quantitative Characterization of Interlayer Interference and Productivity Prediction of Directional Wells in the Multilayer Commingled Production of Ordinary Offshore Heavy Oil Reservoirs. Petroleum 
Exploration and Development, 42, 488-495. https://doi.org/10.1016/S1876-3804(15)30046-X

[16] Wang, D. (1985) Slicing Production Theory. Petroleum Industry Press, Beijing.

[17] Zhou, S. (2009) The Typical Development Practice of Chinese Offshore Oilfield. Petroleum Industry Press, Beijing, 28-29.

[18] Wang, S., Geng, Z. and An, G. (2017) A New Method of Determining the Interlayer Coefficient in Offshore Heavy Oil Reservoir. China Offshore Oil and Gas, 29, 90-95.

[19] Xu, J., Zhang, J., Cheng, L., et al. (2016) The Dynamic Characterization and Application of Interlayer Interference for Sandstone Heavy Oil Multilayer Commingled Producing. China Offshore Oil and Gas, 28, 48-54.

[20] Zhao, Y. (1983) A Discussion on the Interlayer Interference in Water Injection Wells. Petroleum Exploration and Development, 10, 64-69.

[21] Zhang, S. (1984) A Discussion on the Interlayers Interference in a Water Injection Well. Petroleum Exploration and Development, 11, 56-60.

[22] Wang, G., Li, L., Wang, P., et al. (2012) One New Method of Equivalent Simulation of Start-Up Pressure in Numerical Simulation Software. Science Technology and Engineering, 12, 165-167.

\section{Nomenclature}

PIIF, Dimensionless

$S P I, \mathrm{~m}^{3} /(\mathrm{Day} \cdot \mathrm{MPa} \cdot \mathrm{m})$

RIIF, Dimensionless

$R F$, Dimensionless

$G, \mathrm{MPa} / \mathrm{m}$

$K, \mathrm{mD}$

$\mu_{o}, \mathrm{mPa} \cdot \mathrm{s}$

Greek letters

1

o

sli

mli

soi

moi

upper

lower

viso
Productivity interlayer interference factor

Specific productivity index

Oil recovery interference factor

Oil recovery

Pseudo start pressure gradient

Formation permeability

Oil viscosity under formation conditions

water + oil

oil

separated production for fluids

mingled production for fluids

separated production for oil

mingled production for oil

the upper layer

the lower layer

oil viscosity 